\title{
O USO DO LABORATÓRIO VIRTUAL COMO ESTRATÉGIA PARA A ABORDAGEM INVESTIGATIVA NO ENSINO DE BIOLOGIA
}

\author{
The Use of Virtual Laboratory as a Strategy for the Investigative Approach in Biology \\ Teaching
}

\author{
Francisco de Assis José de Oliveira ${ }^{1}$ \\ Kênio Erithon Cavalcante Lima² \\ Silvana Gonçalves Brito de Arruda ${ }^{3}$
}

\begin{abstract}
Resumo: A necessidade de inclusão das Tecnologias Digitais da Informação e da Comunicação às práticas pedagógicas é crescente para atender a uma geração de jovens, cada vez mais, tecnológica. Nesse sentido, o presente estudo teve como objetivo avaliar a aplicabilidade do laboratório virtual numa perspectiva investigativa em uma Sequência Didática Interativa (SDI) para o estudo de Bioquímica no contexto da obesidade. A proposta metodológica adotada foi baseada tanto na intervenção pedagógica de um laboratório virtual e quanto nos estudos de caso aplicados à uma SDI sobre a temática obesidade com estudantes do $1^{\circ}$ Ano do Ensino Médio. Os resultados foram construídos por decorrências das intervenções dos estudos de caso, nas simulações, nos cálculos de IMC, ratificados na comparação dos resultados dos questionários no início e no término da SDI. Constatamos que o uso dessa ferramenta tecnológica, com simulações, permitiu que os estudantes desenvolvessem etapas de um processo investigativo e melhor compreendessem os conteúdos abordados, contribuindo no fomento de novas aprendizagens, o que confirma a importância de tecnologias educativas no processo de ensino e aprendizagem dos conhecimentos biológicos.
\end{abstract}

Palavras-chave: Ensino por Investigação. Simulações Virtuais. Estratégia Pedagógica. Tecnologias Digitais.

Abstract: There is a growing need to include Digital Information and Communication Technologies into pedagogical practices to serve an increasingly technological generation of young people. In this sense, the present study aimed to evaluate, in an investigative perspective, the applicability of virtual laboratory in an Interactive Didactic Sequence (IDS) for the study of

\footnotetext{
${ }^{1}$ Mestre em Ensino de Biologia pela Universidade Federal de Pernambuco (UFPE) e Professor de Biologia da Secretaria de Educação e Esportes do Estado de Pernambuco (SEE). Orcid. https://orcid.org/0000-0002-30986355. E-mail: assisbiologia@gmail.com

${ }^{2}$ Doutor em Educação. Professor Adjunto III do Núcleo de Ciências Biológicas - Centro Acadêmico de Vitória da Universidade Federal de Pernambuco. Docente no Programa de Pós-Graduação em Educação (PPGEdu/UFPE) e no Programa Mestrado Profissional em Ensino de Biologia (PROFBIO/UFPE), atuando na área de Educação e em Ensino de Biologia e de Ciências. http://orcid.org/0000-0001-7434-7013. E-mail: kenio.lima@ufpe.br

${ }^{3}$ Doutora em Nutrição. Professora Associada II do Curso de Nutrição - Centro Acadêmico de Vitória da Universidade Federal de Pernambuco. Docente e Vice-Coordenadora do Programa de Mestrado Profissional em Ensino de Biologia (PROFBIO/UFPE), atuando na área de Ensino de Biologia e de Nutrição. http://orcid.org/0000-0002-9699-9861. E-mail: silvana.arruda@ufpe.br.
} 
Biochemistry in the context of obesity. The methodological proposal adopted was based on both the pedagogical intervention of virtual laboratory and on case studies applied in an Interactive Didactic Sequence on the topic of obesity with first year high school students. The results were constructed as a consequence of case studies, investigations, simulations, BMI calculations and were confirmed by comparing the answers of the questionnaires at the beginning and at the end of the IDS. The findings showed that the use of this technological tool with simulations, allowed students to develop stages of an investigative process and better understanding the contents covered, contributing to the promotion of new learning, which confirms the importance of educational technologies in the teaching-learning process of biological knowledge.

Keywords: Teaching by Research. Virtual Simulations. Pedagogical Strategy. Digital Technologies.

\section{Introdução}

O uso das Tecnologias Digitais da Informação e da Comunicação (TDIC) no processo de ensino e aprendizagem ainda pode ser um desafio para os professores de todas as áreas. Dentre tantas possibilidades de aplicação e de finalidades, as TDIC preconizam auxiliar professores e estudantes na dualidade da educação, que é ensinar e aprender, a exemplo do que vem acontecendo neste momento histórico em que a humanidade presencia a pandemia da Síndrome Respiratória Aguda Grave causada pelo vírus SARS-CoV-2. Segundo Valente (2013, p. 39), "entender como as TDIC podem ser úteis no processo de construção do conhecimento significa entender que elas são mais do que ferramentas ou recursos tecnológicos", pois, quando bem exploradas e aplicadas nas estratégias, têm o potencial de ampliar as possibilidades de aprendizagem dos estudantes da cultura digital (LOPES, 2016).

Em um contexto de ensino planejado para a aplicação de recursos tecnológicos dentro de uma realidade atual, com o propósito de melhor oportunizar a aprendizagem dos estudantes, é possível vivenciar a construção e a aplicação de uma Sequência Didática Interativa ${ }^{4}$ (SDI) que construa suas intervenções aplicando e simulando situações para uma aprendizagem mais representativa e significativa aos conceitos e práticas referentes aos diversos conhecimentos científicos. Nesse entendimento, segundo Zabala (1998, p. 18), a Sequência Didática (SD) é "um conjunto de atividades ordenadas, estruturadas e articuladas para a realização de certos objetivos educacionais, que têm um princípio e um fim conhecidos tanto pelos professores como pelos alunos".

Em um contexto de aprendizagem com intervenções diversas, esperadas para uma SD mais interativa, as tecnologias e suas aplicações educacionais se colocam em um espaço de reconhecimento por tudo o que pode nos ofertar e nos auxiliar diante de novos desafios para entender como aplicar seus desdobramentos e usufruir deles sem excluir os estudantes nem abandonar estratégias, recursos e processos historicamente reconhecidos e consagrados no campo da aprendizagem, aplicados em prol da formação educacional e social de todos. Dentro

\footnotetext{
4 A Sequência Didática Interativa (SDI), idealizada por Oliveira (2013), é um instrumento de suporte didáticometodológico educacional que se diferencia da Sequência Didática Investigativa (SDI) por ter como início a aplicação da técnica do Círculo Hermenêutico-Dialético o que possibilita a dialogicidade e a interatividade entre os estudantes, valorizando os pontos de vistas de cada participante na construção e reconstrução do conhecimento acerca do objeto em estudo.
} 
dessa realidade, usufruindo de procedimentos e estratégias já exploradas no campo de saberes das Ciências da Natureza, existe o Laboratório Virtual (LV), que pode viabilizar a organização e a problematização de conhecimentos biológicos em uma perspectiva de abordagem investigativa ao levar os estudantes a analisarem e compararem dados mediante a observação de simulações de fenômenos comuns da nossa realidade. Para esse contexto ser vivenciado como proposta neste estudo, compreenderemos o quanto se faz pertinente vivenciarmos uma Sequência Didática Interativa (SDI), a qual, segundo Oliveira (2013), é:

[...] uma proposta didático-metodológica que desenvolve uma série de atividades, tendo como ponto de partida a aplicação do Círculo Hermenêutico Dialético para identificação de conceitos/definições, que subsidiam os componentes curriculares (temas), e que são associados de forma interativa com teoria(s) de aprendizagem e/ ou propostas pedagógicas e metodológicas, visando a construção de novos conhecimentos e saberes. (OLIVEIRA, 2013, p. 58).

O uso dessa nova ferramenta didático-metodológica contribui para o ensino das Ciências no contexto escolar. De acordo com Freitas (2015), ao aplicar a metodologia da SDI em sala de aula na abordagem da temática sexualidade no Ensino de Ciências por Investigação, constatouse que ela "promoveu a interação e reflexão temática através de conceitos, procedimentos e atitudes; organizou ideias facilitando o diálogo e o debate, com inferência de hipóteses".

Por certo, o ensino de Biologia empreende conteúdos que exigem do estudante um potencial de abstração, dentre esses, pode-se destacar a Citologia, a Bioquímica da Célula, dentre outros. Posto isso, esta proposta de intervenção com aplicação do LV se dará em uma SDI para melhor explorarmos os conteúdos de Bioquímica da Célula em um contexto de estudos sobre a obesidade, na perspectiva de abordarmos recursos e estratégias de modo mais investigativo, dinâmico, lúdico e significativo aos estudantes.

\section{O uso das tecnologias digitais da informação e comunicação no processo de ensino e aprendizagem}

A inserção das TDIC às práticas pedagógicas tornou-se comum e necessária diante da velocidade da geração e da divulgação do conhecimento. Nessa direção, a Base Nacional Comum Curricular (BNCC) sugere, em uma das competências a serem desenvolvidas por todos os estudantes da Educação Básica, que se empreguem criticamente as Tecnologias Digitais de Informação e de Comunicação no desenvolvimento de conhecimentos e na resolução de problemas, de forma significativa, reflexiva e ética, nos diversos contextos de comunicação em que ocorram o acesso e a divulgação de informações (BRASIL, 2018). Considerando as perspectivas prescritas na BNCC e destacando a visão de Gómez (2015) diante do cenário em pauta, em que as pessoas estão cercadas por uma gama de conhecimentos e informações em tempo real, a compreensão dos processos de ensino e aprendizagem reivindica o uso das Tecnologias da Informação e Comunicação (TIC) para maior apropriação dos conhecimentos existentes e necessários à formação e à integração dos estudantes no contexto social hodierno.

Sob o ponto de vista de Afonso (2002), essas TIC são uma expressão para representar a expansão de ambas as áreas, a da microinformática e a da conexão de computadores em rede por meio da internet, expansão essa ocorrida no final das décadas de 1970 para aquela área e de 1980 para esta, respectivamente, as quais, devido ao estabelecimento da tecnologia digital construída ainda no final do século XX, passam a ser denominadas, dentro de uma adequação 
para a real aplicação e o apropriado contexto na atualidade, de Tecnologias Digitais da Informação e da Comunicação. Na concepção de Kenski (2011), as TIC são procedimentos, métodos e equipamentos para processar informação e comunicação, os quais correspondem a qualquer tipo de tecnologia existente que possibilite, ao ser humano, interações entre a informação e a comunicação, resultantes da fusão de três grandes vertentes técnicas: a informática, as telecomunicações e as mídias eletrônicas (BELLONI, 2005). Por essa realidade - a qual chega aos diversos espaços de aprendizagem e traz uma diferencial velocidade de construção e disseminação do conhecimento e das novidades que implicam severas mudanças sociais na cultura humana -, é cada vez mais imprescindível que o professor esteja capacitado a lidar com essas novas demandas e com esses desafios contemporâneos.

Acerca dessas inovações, alguns autores denominam que essas Novas Tecnologias da Informação e da Comunicação (NTIC) se materializam em vídeos, programas educativos na televisão e no computador, bem como em sites educacionais, softwares diferenciados, entre outros meios e recursos (KENSKI, 2011; COSTA, 2014). Em razão de concepções diferentes para esses recursos tecnológicos (TDIC, TIC, NTIC), nosso recorte conceitual adotará a designação TDIC, concordando com Afonso (2002), no entendimento de que o mundo experiencia a era digital. Tal momento modifica o estilo de vida das pessoas por transformar a forma de se comunicar e de se lidar com a informação (VALENTE, 2013), o que nos faz entender que a sigla TDIC não só melhor corresponde aos conceitos mencionados e aglutina- se a eles, bem como melhor significa o que trabalharemos neste estudo.

Sob o ponto de vista de Gómez (2015), a partir do momento em que a informação é produzida, transmitida, utilizada de diversas formas, modificada e renovada constantemente, novas formas de ler, escrever, pensar, ensinar e aprender se transformam. Dessa forma, é importante que o professor inove, aceite novos desafios e faça uso desses recursos tecnológicos de modo que o seu estudante possa desenvolver aptidões. Nesse sentido, é fundamental uma apropriação maior por parte dos docentes das referências metodológicas e didáticas que orientem a melhor dessas tecnologias e das estratégias, então, atreladas para o contexto escolar. Outro aspecto a ser considerado para a inclusão das TDIC às práticas pedagógicas é o perfil da nova geração estudantil, a qual nasceu na era digital e tem a tecnologia impregnada em seu cotidiano, como em smartphones, computadores, notebooks, tablets, internet, redes sociais, entre outras formas de materialização das TDIC (LOPES, 2016; OLIVEIRA, et al., 2017). Segundo Bonilla e Pretto (2015), os estudantes de todas as classes sociais vivem, direta ou indiretamente, o contexto da cultura digital, o que só tem aumentado o número de jovens interconectados, principalmente, por smartphones.

Nesse sentido, a mediação das TDIC na sala de aula tem o poder de chamar a atenção dos estudantes da "Geração Z" ou, segundo Prensky (2001), "nativos digitais", facilitando o processo de ensino e aprendizagem dos conceitos biológicos de forma mais significativa. Valente (2013) também destaca que o uso das TDIC é importante porque amplia o repertório de possibilidades a que o estudante pode recorrer para expressar e representar seu conhecimento. Para Costa (2014), as tecnologias (TDIC) utilizadas nas aulas devem ser empregadas de maneira criteriosa e significativa, pois, quando adequadamente incorporadas às práticas pedagógicas, são recursos lúdicos (SILVA; BARBOSA, 2016).

Nesse sentido, no referente ao aspecto lúdico atrelado à tecnologia, muitas dessas exploradas para a educação, Gomes (2016) destaca que as brincadeiras e a sua ludicidade foram sofrendo mudanças com o passar do tempo, influenciadas principalmente pelo desenvolvimento tecnológico, de tal forma que a "virtualização do lúdico" (GOMES, 2016, p. 150), quando empregada de maneira adequada às práticas pedagógicas, também "proporciona um meio real de aprendizagem" (GOMES, 2016, p. 152). Ainda de acordo com Gomes (2016), a inclusão de 
brinquedos eletrônicos foi, aos poucos, provocando mudanças na cultura lúdica, ao ponto de brincadeiras consagradas por gerações, como rodinha, ciranda, amarelinha, cabo de guerra, passa-anel, cabra-cega, bolinha de gude, pião, pipa e tantas outras, serem trocadas por jogos eletrônicos, videogames, smartphones, com seus diversos aplicativos, tablets, entre outros.

Sob a ótica de Valente (2013), a partir do momento em que as tecnologias passam a ser aplicadas como ferramentas cognitivas, precisam estar integradas às atividades curriculares que os discentes desenvolvem. Ratificando essa percepção, Kenski (2011) destaca que, para surtir o efeito desejado em prol da educação, não apenas basta usá-las, é preciso também saber empregá-las de forma pedagogicamente correta, avaliando-as e planejando-as, considerando as particularidades de cada recurso a ser utilizado e os objetivos a serem alcançados. Assim, a mediação das tecnologias na escola pode se transformar em "espaços ricos de aprendizagens significativas, presenciais e digitais, que motivem os alunos a aprender ativamente, a pesquisar o tempo todo, a serem proativos, a saberem tomar iniciativas e interagir" (MORAN, 2013, p. $31)$.

No entendimento sobre a teoria da aprendizagem significativa, define-se como a apropriação de significados e a ocorrência de mudanças na estrutura cognitiva de forma organizada e não transitória à medida que o estudante realiza atividades, desenvolvidas em diferentes momentos e situações distintas, utilizando-se de conhecimentos assimilados (AUSUBEL; NOVAK; HANESIAN, 1980). Para se efetivar essa perspectiva de aprendizagem, cabe ao professor atuar na mediação dos processos, oportunizando as condições favoráveis à assimilação e à acomodação de novos conhecimentos, o que vem a reestruturar o cognitivo do estudante. Se o processo for favorável, constata-se, diante da teoria da aprendizagem significativa, que ocorreu o ancoramento de novas informações às estruturas mentais constituintes de conhecimentos pré-existentes, estabelecendo-se subsunçores modificados pela ampliação dos conhecimentos já alicerçados (AUSUBEL; NOVAK; HANESIAN, 1980). Na concepção de Prensky (2010, p. 204), com perspectivas à aprendizagem significativa, compreende-se que "o papel da tecnologia nas nossas salas de aula é o de apoiar a nova pedagogia a partir da qual os alunos ensinam a si mesmos com a orientação do professor". Sob essa ótica, o professor é o mediador da aprendizagem do estudante e a tecnologia deve ser usada como uma ferramenta e/ ou recurso mediador e facilitador, que auxilia o docente a orientar o estudante a aprender a aprender.

\section{O Laboratório Virtual e seus desdobramentos como ferramenta pedagógica}

O Laboratório Virtual (LV) é uma plataforma digital (AMARAL, et al., 2011) que tem como característica a capacidade de simular aspectos de um mundo real por meio de um mundo virtual, proporcionando a interatividade do usuário com o mundo virtual (ZARA, 2011; HERPICH; TAROUCO, 2016). Dessa forma, o uso do LV permite simular variadas etapas da execução de um experimento, manipulando, controlando e modificando dados e variáveis (MELO; OSSO JR, 2008). O uso desse Laboratório Virtual vem assumindo destaque no campo dos recursos tecnológicos educacionais disponíveis para o processo de ensino e aprendizagem das Ciências da Natureza por possibilitar a realização de modelos experimentais através de simulação virtual. Segundo Gregório, Oliveira e Matos (2016), os simuladores são ferramentas computacionais que possuem grande potencial para a promoção do processo de aprendizagem por meio da motivação e interação dos estudantes e professores.

Nesse caso, o Laboratório Virtual reúne as três vertentes técnicas destacadas por Belloni (2005) - a informática, as telecomunicações e as mídias eletrônicas - de que necessitamos, possibilitando-nos visualizar aquilo que é concreto por meio de uma realidade virtual. Também 
se apresenta como uma transformação inovadora para aulas das disciplinas das áreas de Ciências da Natureza, de Tecnologia, de Engenharia e de Matemática. De forma prática, o laboratório se faz, em muitos dos casos, um recurso necessário ao suprimir a carência tanto de recursos para o desenvolvimento de atividades práticas de laboratório e/ ou de campo quanto de tempo necessário para o desenvolvimento e construção de resultados de experimentos. Assim, de acordo com Braga (2001), a realidade virtual é uma experiência imersiva e interativa que se baseia em imagens 3D, às quais, por meio do computador, são geradas em tempo real, aproximando o mundo real do imaginário, simulado pela tecnologia.

Sob essa ótica, a criação de um ambiente realístico de um experimento possibilita que o estudante, diante de um problema proposto, possa interagir e tomar decisões, analisar dados, compará-los, levantar hipóteses, testá-las, construir e reconstruir conceitos, dando-lhes as ferramentas e as condições necessárias para uma aprendizagem com maior autonomia. Além disso, possibilita a construção de protocolos consonantes com os princípios científicos do ensino por investigação mediante simulações experimentais em realidade virtual de forma dinâmica e significativa, por meio de uma linguagem própria da cultura digital. Nesse aspecto, Melo e Osso Jr (2008), ao se referirem às características do LV, ressaltam que:

\begin{abstract}
A mais forte característica de um LV (e das tecnologias de RV que ele utiliza) é que permite a simulação de conceitos científicos, transpondo-os do mundo abstrato das ideias para modos sensorialmente perceptíveis, de modo a criar um ambiente com o qual o aluno possa interagir, inclusive, colocando-se virtualmente dentro do laboratório simulado, o que lhe assegura condições para que possa aprender por meio de sua própria experiência (ainda que 'dentro de um mundo virtual'), uma meta preconizada por cientistas cognitivistas (MELO; OSSO JR, 2008, p. 15).
\end{abstract}

Nessa perspectiva, o LV pode contribuir, a depender de como é explorado pelo professor e estudantes, com a melhoria do processo de ensino e aprendizagem ao se tornar uma ferramenta que facilita a aplicação de estratégias adequadas e adaptadas às demandas da cibercultura, perpassando as colunas tradicionais de ensino dos conteúdos para desenvolver competências e habilidades dessa geração, como preconiza a BNCC (BRASIL, 2018).

A mediação dessa tecnologia, que era pouco explorada no Brasil (MELO; OSSO JR, 2008), apresentou um aumento considerável devido ao investimento de diversas universidades e empresas no desenvolvimento de softwares dessas simulações em ambientes virtuais, pois esses laboratórios fornecem recursos importantes às aulas teóricas (FONSECA, et al., 2013), tanto para a análise de fenômenos quanto para a aplicação de conceitos e práticas em objetos de estudos das Ciências. Com a expansão desse campo tecnológico, várias áreas do conhecimento como a engenharia, a mecânica, a física e a química apropriam-se cada vez mais dos recursos do LV, o que o tornou um uso constante em seus estudos e propostas de intervenção (FONSECA, et al., 2013; LAZALDE; MONREAL; BONILLA, 2016; HERPICH; TAROUCO, 2016; SANTOS; COSTA, 2016; SILVA; NUNES; MERCADO, 2016). Na educação básica, é crescente o uso do LV como ferramenta que auxilia o estudante a compreender conteúdos que requerem uma capacidade de abstração dos fenômenos envolvidos (FONSECA, et al., 2013). A realização do experimento, a manipulação dos seus parâmetros, a interação com o objeto de sua aprendizagem e a comunicação estabelecida entre os participantes leva a superação das dificuldades de aprendizagem dos estudantes sobre esses assuntos, uma vez que possibilita a visualização simulada do fenômeno em estudo. 
É importante frisar que o laboratório físico também é uma ferramenta importante de experimentação, portanto, não se trata de trocá-lo, e sim de acrescentar outras condições e uma diferente estratégia didática (MELO; OSSO JR, 2008) por considerarmos que a realização de aulas práticas oportuniza e acresce na aprendizagem dos estudantes de forma que seja mais dinâmica, tornando os processos mais atrativos. Por certo, sabe-se que muitas escolas não possuem o laboratório físico, já que o valor de implantação e manutenção é elevado, ou, quando possuem, esbarram nas dificuldades com a disponibilidade de materiais, com o pouco espaço e com a ausência de suporte técnico aos professores. Assim, o uso do LV torna-se propício por suas características: mínimo ou nenhum custo para a escola; acessibilidade on-line e off-line, seja em sala de aula, seja em outro lugar e em qualquer momento; complementação das atividades de aprendizagem, colocando os estudantes como protagonistas da ação e mais seguros ao realizarem os experimentos que apresentam riscos, sobretudo quando são usadas substâncias inflamáveis.

Com essa compreensão, o projeto Physics Educacional Technology (PhET), desenvolvido pela Universidade do Colorado, aparece como uma possibilidade didática para uma abordagem investigativa adequada à realidade das escolas públicas brasileiras por disponibilizar gratuitamente em sua plataforma diversos laboratórios virtuais nas áreas da Física, da Biologia, da Química, das Ciências e da Matemática, com vários conteúdos para cada componente curricular citado. Vale ressaltar que algumas pesquisas que utilizaram os laboratórios virtuais da plataforma PhET em sala de aula têm demonstrado bons resultados nas áreas de Física (MACÊDO; DICKMAN; ANDRADE, 2012; SANTOS; DICKMAN, 2019), Biologia (GREGÓRIO; OLIVEIRA; MATOS, 2016) e Química (MENDES; SANTANA; JÚNIOR, 2017).

Em um recorte, condizente ao nosso estudo, destacamos que o ensino de Biologia para o Ensino Médio, previsto na BNCC na área de Ciências da Natureza e suas Tecnologias, permeia uma visão de ensino e de aprendizagem articulada com a Física e com a Química. Nesse contexto, colocam-se como propostas para essa etapa da educação básica brasileira os processos e as práticas de investigação por meio de recursos e métodos de estudo que levem o estudante: a reconhecer problemas; a construir questionamentos para a comprovação ou negação; a elaborar hipóteses e a testá-las (BRASIL, 2018). Para isso, o estudante deverá ser capaz de realizar algumas tarefas/ações: idealizar e executar atividades experimentais e pesquisas de campo, definir e usar equipamentos de medida, coletar, manusear e analisar dados, verificar informações ou variáveis significantes, relatar, avaliar e comunicar conclusões e, a partir dessas inferências, criar ou sugerir ações para solucionar essas problemáticas (BRASIL, 2018).

Nessa perspectiva, o uso do laboratório virtual PhET torna-se uma ferramenta pedagógica viável ao desenvolvimento de uma abordagem investigativa, uma vez que possibilita que o estudante formule hipóteses, analise dados, compare resultados, modifique variáveis, teste suas hipóteses e reformule conceitos. Nos pressupostos de uma aprendizagem construída por uma estratégia didática como atividade investigativa, dentro da percepção de Azevedo (2015), a atuação do estudante não pode se "limitar apenas ao trabalho de manipulação ou observação, ela deve também conter características de um trabalho científico: o aluno deve refletir, discutir, explicar, relatar, o que dará ao seu trabalho as características de uma investigação científica" (AZEVEDO, 2015, p. 21). Sob o ponto de vista de Sasseron (2013), 
Uma investigação científica pode ocorrer de maneiras distintas e certamente o modo como ocorre está ligado às condições disponibilizadas e às especificidades do que se investiga, mas é possível dizer que toda investigação científica envolve um problema, o trabalho com dados, informações e conhecimentos já existentes, o levantamento e o teste de hipóteses, o reconhecimento de variáveis e o controle das mesmas, o estabelecimento de relações entre informações e a construção de uma explicação. (SASSERON, 2013, p. 43).

Nesse sentido, é importante que o professor busque situações-problema inovadoras que despertem a curiosidade, o senso crítico, promovam a interação e a cooperação entre os estudantes durante o processo de ensino e aprendizagem, de forma a tornar esta relação significativa. De acordo com Montanini, Miranda e Carvalho (2018, p. 290), "as atividades investigativas potencializam o desenvolvimento do aluno e oportunizam a aprendizagem significativa", o que atende a pressupostos de bases legais como a BNCC (BRASIL, 2018). Assim, diante do que foi exposto, este estudo tem como objetivo avaliar a aplicabilidade do Laboratório Virtual na perspectiva investigativa em uma Sequência Didática Interativa para o estudo de Bioquímica, assumindo, como contexto de aplicação, a temática obesidade.

\section{Proposta metodológica}

O presente estudo é fruto de resultados obtidos em atividades práticas constituintes da dissertação de mestrado do primeiro autor no Programa de Pós-Graduação em Ensino de Biologia (PROFBIO), que aborda o uso de um Laboratório Virtual como ferramenta estratégica na aplicação de intervenções em uma Sequência Didática Interativa para o ensino de Bioquímica na disciplina Biologia no Ensino Médio com enfoque na temática obesidade.

O percurso metodológico pautou-se na aplicação de uma Sequência Didática Interativa (SDI) articulada ao laboratório virtual, em uma turma do $1^{\circ}$ Ano do Ensino Médio Regular, do turno da manhã, de uma escola da Rede Estadual de Ensino de Pernambuco, em um contexto de aula presencial - antes da Pandemia COVID-19. Participaram efetivamente 22 estudantes, numa faixa etária entre 14 e 18 anos, que entregaram o Termo de Consentimento Livre e Esclarecido e o Termo de Assentimento Livre e Esclarecido, devidamente assinados pelos seus responsáveis legais e por eles mesmos. A pesquisa foi submetida ao Comitê de Ética da Universidade Federal de Pernambuco (UFPE) e aprovada com o número 207033197.0000.9430. O estudo completo encontra-se no Repositório Digital da UFPE https://repositorio.ufpe.br/handle/123456789/39334?mode=full

A pesquisa teve caráter intervencionista de abordagem qualitativa que buscou analisar a aplicabilidade do LV como estratégia para o ensino de conteúdos de Bioquímica na perspectiva investigativa. Conforme Oliveira (2016, p. 37), a "abordagem qualitativa é um processo de reflexão e análise da realidade através da utilização de métodos e técnicas para compreensão detalhada do objeto de estudo em seu contexto histórico". Foram utilizados como instrumentos de coleta de dados tanto questionários aplicados no início e ao término da SDI como também a análise dos estudos de caso realizados pelos estudantes em momento posterior. O recurso de estudo utilizado para a realização dessa pesquisa foi o Laboratório Virtual PhET de Biologia intitulado Comer e Exercitar-se ${ }^{5}$.

\footnotetext{
5 O laboratório virtual Comer e Exercitar-se desenvolvido e disponibilizado pela plataforma PhET (Physics Education Technology). Disponível em: https://phet.colorado.edu/sims/cheerpj/eating-and-exercise/latest/eatingand-exercise.html?simulation=eating-and-exercise\&locale=pt_BR é uma das simulações interativas gratuitas na
} 
A intervenção pedagógica ocorreu em seis momentos, com uma hora-aula de 50 minutos cada um. No primeiro momento, os estudantes responderam a um Questionário Pré-Teste com questões objetivas e discursivas (Apêndice A); em seguida, foi realizada a problematização do tema por meio de uma exposição dialogada, questionando-os sobre o que leva uma pessoa a ficar com sobrepeso ou obesa. Após a explanação, a turma foi dividida em 5 grupos representados por cores (azul, amarela, laranja, verde e vermelha), que passaram a caracterizar o nome dos grupos durante toda a SDI. No segundo momento, ocorreu um debate acerca dos principais pontos discutidos no fórum disponibilizado na Google Classroom $^{6}$ sobre o referido tema. No terceiro momento da sequência, foi feita uma exposição dialogada com apresentação de slides sobre o conteúdo "Bioquímica da Célula", com conceitos básicos de nutrição. No quarto momento, os estudantes, organizados em grupo, realizaram uma atividade prática do cálculo do próprio Índice de Massa Corporal (IMC), usando o Laboratório Virtual Comer e Exercitar-se.

No quinto momento, que serviu de proposta mais representativa aos resultados analisados neste estudo, os estudantes se organizaram nos respectivos grupos e receberam, cada um, um estudo de caso. Cada problemática continha uma das três situações com adolescentes do sexo feminino ou masculino descritas a seguir: a primeira, o jovem praticava atividade física regularmente, apresentando massa corporal normal e, de repente, deixava de realizá-la; a segunda, o adolescente não praticava exercício físico algum, apresentando um IMC classificado como obesidade, mas que passou a fazer uma atividade esportiva; e a terceira, o jovem não praticava atividade física alguma, apresentando um IMC classificado como abaixo do peso e que passou a realizar um exercício físico. Para responder aos questionamentos referentes aos estudos de caso, tiveram que descobrir o IMC com os dados fornecidos. Como desafio subsequente, as equipes tinham que elaborar uma lista de alimentos para cada uma das três principais refeições - café da manhã, almoço e jantar. Os cardápios precisavam conter as calorias necessárias para satisfazer as necessidades calóricas de forma a manter o IMC da situação proposta, bem como fazer as devidas adequações quanto à prática de atividade física, usando o Laboratório Virtual PhET Comer e Exercitar-se.

Para a análise de conteúdo dos estudos de caso foram definidas quatro etapas avaliativas: 1. conclusão da atividade; 2 . cálculo do IMC; 3 . construção da lista alimentar de acordo com as necessidades calóricas; e 4. adequação da atividade física. Cada uma delas foi analisada usando três critérios avaliativos: I. realizado; II. realizado parcialmente; e III. não realizado. Isso nos possibilitou explorar e avaliar o quanto de conhecimentos sobre a Bioquímica da Célula os estudantes assimilaram e souberam aplicar nas situações de estudo propostas.

O primeiro critério - "realizado" - foi atribuído às etapas concluídas com êxito pelos grupos. Em relação à Etapa 1 - "conclusão da atividade" -, foi avaliado também como "realizado" quando o grupo realizou parcialmente apenas uma etapa avaliativa ou deixou de executar somente uma das etapas, ou ainda se deixou de executar uma e realizou parcialmente outra. O segundo critério - "realizado parcialmente" - foi empregado para as etapas que foram realizadas, mas que apresentavam alguns erros. No caso da Etapa 1 - "conclusão da atividade" -, foi considerado "realizado parcialmente" quando o grupo deixou de fazer duas das outras

área de Biologia. As simulações baseiam-se no envolvimento dos estudantes por meio de um ambiente intuitivo, estilo jogo, em que os estudantes aprendem mediante exploração e descoberta.

${ }^{6}$ Para maximizar o tempo da Sequência Didática Interativa, foi utilizado a Google Classroom, que é uma sala de aula virtual gratuita da Google, lançada em 2014, que possibilita a comunicação entre professor e estudante, além dos muros da escola. O professor pode disponibilizar materiais de apoio (textos, livros, vídeos, entre outros), aplicar atividades, fazer acompanhamento e realizar o feedback das atividades. O acesso dele é permitido apenas a professores, estudantes e profissionais cadastrados por meio do e-mail do Gmail. 
três etapas avaliativas ou quando realizou parcialmente duas ou três etapas. O terceiro critério - "não realizado" - foi usado quando as etapas não foram executadas.

No sexto momento, cada grupo elaborou uma produção textual com o tema "Desafios do combate à obesidade na adolescência", como fechamento da Sequência Didática Interativa. Por último, os estudantes responderam individualmente ao Questionário Pós-Teste, o qual apresenta, como características, questões do tipo objetivas, discursivas e semiestruturadas (Apêndice B).

\section{Resultados e discussão}

A nossa proposta de Sequência Didática Interativa se estruturou com algumas estratégias e recursos que viabilizaram a interação dos estudantes com a temática da obesidade, assumindo como conhecimento necessário a Bioquímica da Célula. Algumas das intervenções iniciais buscaram diagnosticar saberes anteriores, bem como estabelecer a organização de saberes necessários às intervenções finais com os estudos de caso.

Os estudos de caso foram usados como estratégia didática que possibilitaram aos estudantes, ao final da SDI, não só confrontarem suas suposições e ideias construídas a partir das discussões levantadas durante a apresentação do tema no primeiro momento dessa, como também compararem seus conhecimentos posteriores com os assuntos debatidos no decorrer dos outros momentos que antecederam a aplicação do Laboratório Virtual por meio da análise de uma situação-problema. Assim, baseado nos critérios avaliativos adotados, observou-se que os Grupos Azul, Verde e Amarelo realizaram todas as etapas avaliativas. Os Grupos Laranja e Rosa deixaram de executar apenas uma das etapas avaliativas: "4. adequação da atividade física" e "2. cálculo do IMC", respectivamente (Quadro 1). Percebeu-se que a realização das situações-problema foi desencadeadora para que os estudantes desenvolvessem uma abordagem investigativa (BRASIL, 2018).

Quadro 1 - Estudos de caso do quinto momento da Sequência Didática Interativa

\begin{tabular}{|c|c|c|c|c|c|}
\hline \multirow[b]{2}{*}{ Grupos } & \multirow[b]{2}{*}{$\begin{array}{l}\text { Critério de } \\
\text { avaliação }\end{array}$} & \multicolumn{4}{|c|}{ Etapas dos estudos de caso avaliadas } \\
\hline & & $\begin{array}{c}\text { Conclusão } \\
\text { da } \\
\text { atividade }\end{array}$ & $\begin{array}{l}\text { Cálculo } \\
\text { do IMC }\end{array}$ & $\begin{array}{l}\text { Construção da lista } \\
\text { alimentar de } \\
\text { acordo com as } \\
\text { necessidades } \\
\text { calóricas }\end{array}$ & $\begin{array}{l}\text { Adequação da } \\
\text { atividade física }\end{array}$ \\
\hline \multirow{3}{*}{$\begin{array}{c}\text { Grupo } \\
\text { Azul }\end{array}$} & Realizado & & & & \\
\hline & $\begin{array}{c}\text { Realizado } \\
\text { parcialmente }\end{array}$ & & & & \\
\hline & Não realizado & & & & \\
\hline \multirow{3}{*}{$\begin{array}{l}\text { Grupo } \\
\text { Laranja }\end{array}$} & Realizado & & & & \\
\hline & $\begin{array}{c}\text { Realizado } \\
\text { parcialmente }\end{array}$ & & & & \\
\hline & Não realizado & & & & \\
\hline \multirow{3}{*}{$\begin{array}{l}\text { Grupo } \\
\text { Verde }\end{array}$} & Realizado & & & & \\
\hline & $\begin{array}{c}\text { Realizado } \\
\text { parcialmente }\end{array}$ & & & & \\
\hline & Não realizado & & & & \\
\hline \multirow{4}{*}{$\begin{array}{c}\text { Grupo } \\
\text { Rosa }\end{array}$} & Realizado & & & & \\
\hline & $\begin{array}{c}\text { Realizado } \\
\text { parcialmente }\end{array}$ & & & & \\
\hline & Não realizado & & & & \\
\hline & Realizado & & & & \\
\hline
\end{tabular}




\begin{tabular}{|c|c|l|l|l|l|}
\hline \multirow{2}{*}{$\begin{array}{c}\text { Grupo } \\
\text { Amarelo }\end{array}$} & $\begin{array}{c}\text { Realizado } \\
\text { parcialmente }\end{array}$ & & & & \\
\cline { 2 - 5 } & Não realizado & & & & \\
\hline
\end{tabular}

Fonte: Elaborado pelos autores (2020).

Nesse ponto, partimos do pressuposto de que toda atividade investigativa requer um problema (SASSERON; CARVALHO, 2008; TRIVELATO; TONIDANDEL, 2015; BRITO; FIREMAN, 2018), o qual leve o estudante a usar "dados, informações e conhecimentos já existentes [assim como realizar] o levantamento e o teste de hipóteses, o reconhecimento de variáveis e o controle delas, o estabelecimento de relações entre informações e a construção de uma explicação" (SASSERON, 2013, p. 43). Nesse sentido, as situações criadas e desenvolvidas pelos estudantes exigiram a realização do cálculo do Índice de Massa Corporal (WHO, 2000), análise e comparação desses dados com informações em quadros e tabelas, simulação de rotinas alimentares baseadas nos dados obtidos, análise da mudança de variáveis, reflexão e explicação diante dessas mudanças com argumentações orais ao final, em uma roda de discussão mediada pelo professor. Desse modo, configura-se com a efetivação dessas ações que realizaram etapas de um processo investigativo, concordante com documentos oficiais e com estudos na literatura pertinente.

No contexto do ensino por investigação, concordando com a BNCC (BRASIL, 2018), os estudantes foram incentivados a realizarem, de forma colaborativa, atividades investigativas. Essa premissa não quer afirmar que esse processo investigativo precise seguir "um conjunto de etapas pré-definidas", como também não deve se limitar às seguintes ações comuns: "manipulação de objetos ou realização de experimentos em laboratório. Ao contrário, pressupõe organizar as situações de aprendizagem partindo de questões que sejam desafiadoras, estimulem o interesse e a curiosidade científica" (BRASIL, 2018 p. 322). Assim, ao longo da realização dos estudos de caso pelos estudantes, observaram-se a motivação, a participação, a interação, a colaboração, a curiosidade e o engajamento na execução das atividades (Figura 1). Dessa forma, constatamos que a abordagem investigativa desenvolvida pelos estudantes foi condizente com a perspectiva de ser a partir de "[...] desafios e problemas abertos e contextualizados, para estimular a curiosidade e a criatividade na elaboração de procedimentos e na busca de soluções de natureza teórica e/ou experimental" (BRASIL, 2018, p. 551).

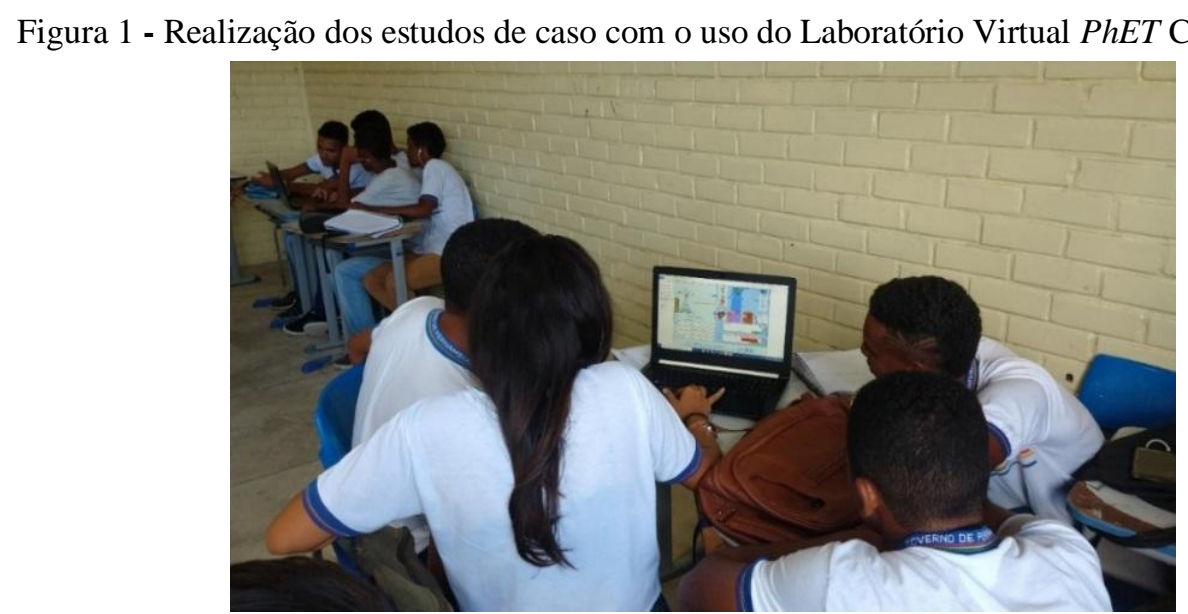

Fonte: Elaborado pelos autores (2019). 


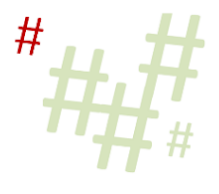

Conforme os dados apresentados no Quadro 1, percebeu-se que o uso do Laboratório Virtual PhET Comer e Exercitar-se foi eficiente por oportunizar que os estudantes dos grupos tivessem bom aproveitamento na execução dessa atividade, uma vez que quase todas as equipes/ grupos conseguiram realizar, em sua totalidade, as etapas avaliadas dos estudos de caso. Também observamos que os estudantes expressaram motivação ao realizarem as simulações no Laboratório Virtual PhET Comer e Exercitar-se pela curiosidade que foi despertada neles e pelo poder que essa tecnologia possui de simular situações reais, do dia a dia deles, o que causou encantamento nos jovens, assim como foi constatado por Santos e Dickman (2019).

Conforme Moran (2013), aprende-se melhor quando se agregam elementos da natureza humana ao processo de aprendizagem, como motivação, interesse e prazer no que se está estudando. Esse é um dos aspectos que levaram Gregório, Oliveira e Matos (2016) a recomendarem o uso das simulações do Laboratório Virtual PhET com uma abordagem investigativa. Segundo os autores, essas estratégias com o LV facilitam o ensino de conteúdos abstratos de Biologia, assim como promove a motivação e a interação entre os estudantes, situações fundamentais para a aprendizagem (GREGÓRIO; OLIVEIRA; MATOS, 2016).

Como a ferramenta virtual foi relacionada ao rol de conhecimentos prévios sobre a área de informática, observou-se o rápido entrosamento e empolgação dos estudantes participantes ao realizarem as simulações. Notou-se ainda a interação e atenção desses ao fazerem observações sobre a análise do gráfico, bem como se divertindo ao assistirem ao boneco que engordava, emagrecia ou morria conforme as mudanças realizadas/ simuladas nos parâmetros de alimentação e de atividade física, o que ratifica a eficácia dessas atividades práticas quando associadas a propostas de ensino por investigação. Nesta descrição, cabe destacar ainda que os estudantes terminaram a atividade muito rápido e continuaram a fazer outras simulações, o que endossa o caráter lúdico e interativo do LV PhET Comer e Exercitar-se, sendo mais um elemento importante que oportuniza a aprendizagem dos participantes.

Nesse contexto estudado, percebemos que as TDIC assumiram o potencial de trazer o lúdico para a sala de aula (SILVA; BARBOSA, 2016), em que o aspecto de entretenimento, quando empregado adequadamente às práticas pedagógicas, pode oportunizar momentos de aprendizagem efetiva, vislumbrando várias possibilidades para o processo educacional (GOMES, 2016). Assim, constatamos que as simulações do Laboratório Virtual apresentam características que, segundo Santos e Dickman (2019, p. 3), "fascinam o jovem estudante, aguçando seu interesse e curiosidade, abrindo ainda a possibilidade de o mesmo (SIC) trabalhar com simulações computacionais em casa e trazer novos fatos à sala de aula", o que oportuniza construir, junto ao objeto de estudo, o poder de causar, no estudante, interesse, motivação e entusiasmo, essenciais na criação de situações favoráveis para uma efetiva aprendizagem (MORAN, 2013).

Com tais resultados, acreditamos que, quando as TDIC são empregadas em sala de aula de forma correta, com critérios, considerando as especificidades de cada recurso, elas podem sim proporcionar uma aprendizagem ativa e significativa (COSTA, 2014; KENSKI, 2011; MORAN, 2013). Nessa perspectiva, o uso do LV PhET Comer e Exercitar-se mostrou- -se como uma ferramenta pedagógica eficaz, uma vez que esse tipo de tecnologia contribuiu à mediação do entendimento de fenômenos que fazem parte do cotidiano dos estudantes, ou seja, da cultura digital (LOPES, 2016; OLIVEIRA, et al., 2017; BONILLA; PRETTO, 2015). Em virtude disso, favoreceu que os estudantes tivessem uma aprendizagem mais participativa, dinâmica e significativa, mostrando que essa é uma "ótima ferramenta para ser utilizada nas escolas públicas brasileiras” (GREGÓRIO; OLIVEIRA; MATOS, 2016, p. 122). 
No último momento das intervenções da SDI, ao final da atividade investigativa e de simulações até então oportunizadas, foi realizada uma roda de discussão mediada pelo professor. Tal momento se fez importante para que os estudantes expressassem oralmente seus conhecimentos, seus pontos de vista diante da problemática da obesidade. No transcorrer da discussão, surgiram várias sugestões dos grupos para solucionar ou minimizar o problema, de forma que muitos falaram ser preciso mais informações aos jovens acerca dos alimentos ou da necessidade de se melhor estimular a prática de atividade física, entre outras. Esse momento, com reflexões, mostrou-se eficiente por permitir que os participantes expressassem suas ideias, posicionamentos e argumentos. Por conseguinte, confirmou-nos o quanto é essencial que o professor viabilize a realização de situações de aprendizagem investigativas que promovam a argumentação estudantil, como as que criamos, com o desenvolvimento de características de um trabalho científico, o que nos oportunizou uma discussão na qual eles expuseram suas ideias, explicações e reflexões (FERRAZ; SASSERON, 2017).

Mediante as colocações dos estudantes, percebeu-se que puderam se posicionar criticamente, o que nos faz afirmar que a abordagem investigativa de que participaram promoveu o protagonismo estudantil por terem proposto "soluções de natureza teórica", (BRASIL, 2018 p. 551). Segundo Costa e Vieira (2006), a participação dos jovens mediante seu envolvimento na busca de soluções de situações-problema de interesse coletivo é uma forma de possibilitar a sua ação protagonista. Assim, ainda diante do diálogo colaborativo, os grupos apresentaram alguns pontos de vista que foram baseados nas observações dos gráficos e do boneco que engordava, emagrecia ou morria durante a simulação, tais como: "a redução da atividade física pode levar à obesidade"; "a atividade física ajuda a reduzir o IMC"; "se o IMC aumentar muito, a pessoa pode morrer"; "reduzir demais a alimentação pode levar à morte"; "a alimentação é importante para manter uma boa saúde".

Percebeu-se que as simulações do Laboratório Virtual PhET Comer e Exercitar-se permitiram uma melhor compreensão dos estudantes sobre os assuntos discutidos em sala de aula, com destaque para a visualização do cálculo do IMC, da proporção dos macronutrientes, da influência do estilo de vida, da atividade física e das escolhas dos alimentos, bem como observar o que acontecia diante das mudanças desses parâmetros. Essa interação entre os estudantes e a ferramenta tecnológica proporcionou que eles pudessem "aprender por meio de sua própria experiência" (MELO; OSSO JR, 2008, p. 15). Dessa forma, fica evidenciado que o LV PhET Comer e Exercitar-se possibilitou visualizar a situação em estudo através da simulação das mudanças dos parâmetros, o que ampliou o poder argumentativo dos estudantes, referentes à temática em estudo - obesidade. Assim, de acordo com Santos e Costa (2016, p. 90), as simulações dos LV produzem "um ambiente rico de aprendizagem levando o aluno a estabelecer relações significativas" referente a um fenômeno estudado.

Em outro recorte deste estudo, no referente aos instrumentos de pesquisa do tipo levantamento, conforme os dados obtidos a partir da aplicação dos Questionários Pré-SDI e Pós-SDI, notou-se que, no começo dessa, apenas 13,64\% dos estudantes responderam que conheciam os macronutrientes. Ao término da sequência, esse número passou para 77,27\%, o que significa um aumento de $63,87 \%$ em relação ao início da SDI.

Em princípio, ainda que essas mudanças de apropriação de conhecimento pelos estudantes representem resultados modestos ou também esperados para outros processos de ensino, trata-se de um resultado construído por estudantes do $1^{\circ}$ Ano do Ensino Médio que não apresentam base consolidada nem entendimento de princípios da Química suficientes para entendimentos mais complexos. Da mesma forma, são resultados que se justificam dentro de um conjunto de outros parâmetros e atividades, a exemplo dos estudos de caso, que os levaram a um entendimento da Bioquímica da Célula não restrito a descrições e classificações de 
nutrientes e seus respectivos alimentos, mas sim do reconhecimento e da relação que estes estabelecem e significam para a qualidade de saúde das pessoas. É nesse mesmo patamar de compreensão que seguimos analisando outras questões e resultados construídos nas intervenções realizadas nesta SDI, analisada com a aplicação do Laboratório Virtual.

Quanto ao conhecimento dos estudantes acerca do macronutriente presente em maior quantidade em alguns alimentos listados, verificou-se que, no início da SDI, o percentual de respostas certas foram carboidratos $1,52 \%$, lipídeos $1,52 \%$ e proteínas $0,00 \%$, o que difere dos resultados no Pós-Teste quando os acertos passaram a ser de 39,39\%, 30,30\% e 53,03\%, respectivamente, o que corresponde a um aumento percentual real nas respostas certas quando comparados ao início da sequência (Figura 2).

Figura 2 - Comparação do conhecimento dos estudantes sobre o macronutriente presente em maior quantidade nos alimentos no início e ao término da Sequência Didática Interativa.

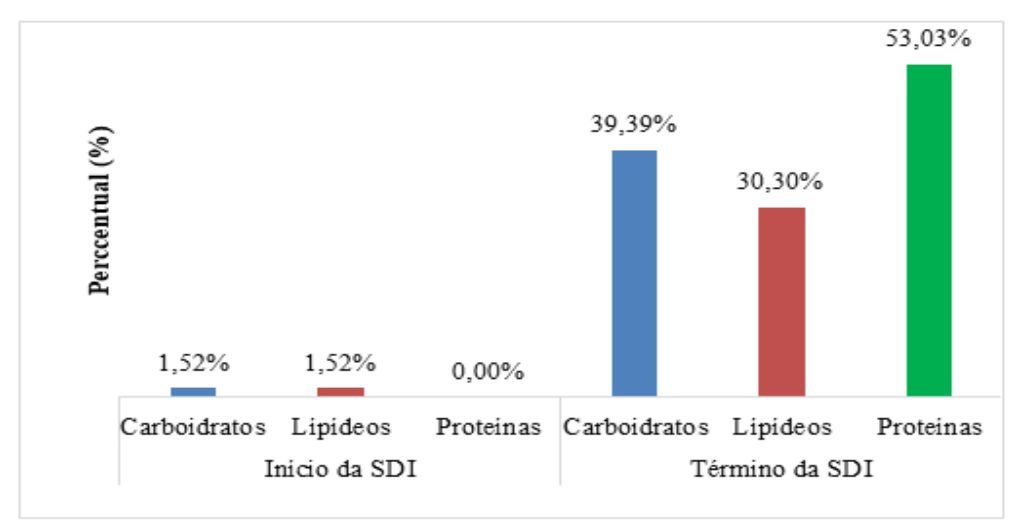

Fonte: Elaborado pelos autores (2020).

Em relação à principal função dos macronutrientes, constatou-se que, no começo da SDI, o percentual de estudantes que responderam conhecê-las foi, para carboidratos, 27,27\%; para lipídeos, $9,09 \%$, e, para proteínas, 40,91\%. Ao término da sequência, esses números aumentaram, na mesma ordem, para 40,91\%, 40,91\% e 59,09\%, obtendo-se um aumento notável no percentual quando comparados ao início da SDI (Figura 3).

Figura 3 - Conhecimento dos estudantes sobre a função dos macronutrientes no início e na conclusão da SDI

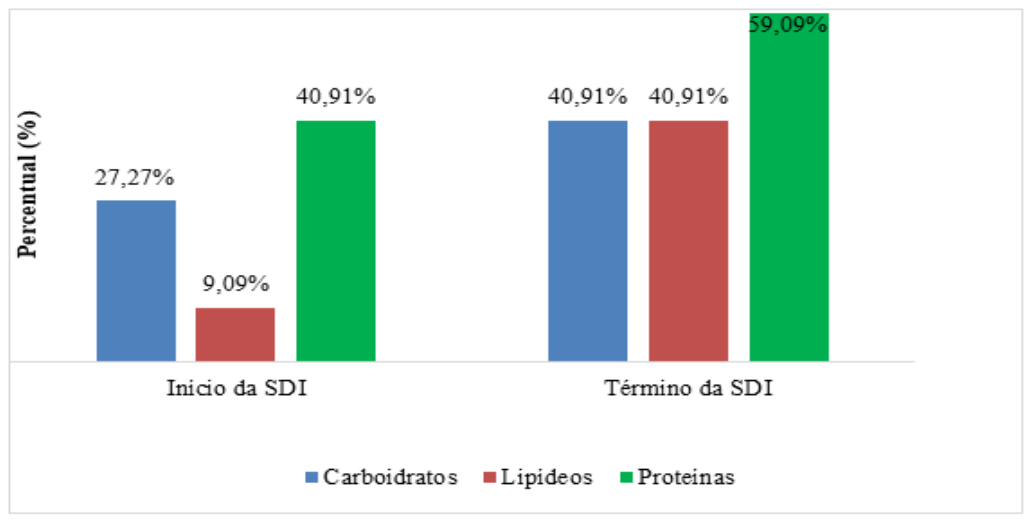

Fonte: Elaborado pelos autores (2020). 
Ficou evidente que as atividades desenvolvidas ao longo da SDI propiciaram que os estudantes passassem a ter, ao término da Sequência, um conhecimento maior dos conteúdos abordados. Como característica a ser considerada, ressaltamos que esses estudantes começaram a estudar Bioquímica da Célula de forma aprofundada no $1^{\circ}$ Ano do Ensino Médio, cujo campo de conhecimento agrega conceitos de duas Ciências, a Biologia e a Química para explicar fenômenos biológicos (GOMES; RANGEL, 2006). Nesse sentido, percebeu-se, pelos resultados dos questionários, que alguns estudantes ainda sentiram dificuldades por se tratar de um assunto que requer conhecimentos básicos da Química. Torna-se um fato quando analisamos pesquisas que mostram o quanto o estudo da Bioquímica causa dificuldades tanto para estudantes da Educação Básica quanto para os do Ensino Superior (GOMES; MESSEDER, 2014), o que implica a necessidade de aprofundamento desses estudos, tanto da Química quanto da Bioquímica, fato que ocorrerá ao longo do Ensino Médio, como evidenciamos com os estudantes participantes deste estudo.

É importante frisar que os resultados citados acima não dizem respeito a uma avaliação tradicional, de mera memorização e classificação (aprovado ou reprovado). Pelo contrário, os dados revelam um processo de construção do conhecimento. Portanto, eles são expressivos por se tratarem de resultados construídos em um caminho que está sendo percorrido por meio de uma aprendizagem mais contextualizada, familiar e aplicável para a vida dos estudantes, como ficou evidenciado pelas relações que os estudantes estabeleceram entre os conteúdos e os conceitos trabalhados em sala de aula com as situações vivenciadas durante a Sequência.

\section{Considerações finais}

São inegáveis as mudanças que as Tecnologias Digitais da Informação e da Comunicação têm provocado na sociedade contemporânea. Na área da Educação, essas transformações trouxeram novas possibilidades de ensinar e aprender. Dessa forma, o uso da TDIC com o Laboratório Virtual PhET Comer e Exercitar-se oportuniza a aplicação de estratégias pedagógicas na perspectiva da abordagem investigativa para o ensino de Biologia. Nesse contexto de aprendizagem, foi possível perceber, nos resultados construídos a partir da resolução dos estudos de caso e com as respostas aos questionários, que os objetivos então traçados para este estudo, materializados nas intervenções propostas, foram alcançados. As situações-problema, em forma de estudos de caso atribuídos aos estudantes, mostraram-se uma atividade eficiente por viabilizar o desenvolvimento de uma abordagem investigativa.

A realização das simulações do LV PhET Comer e Exercitar-se para resolver as situações propostas conduziu os estudantes para a execução de etapas de um processo investigativo, como analisar dados, compará-los com informações em quadros e tabelas, controlar variáveis, relatar suas observações, apresentar seus pontos de vista e propor soluções para um problema durante uma roda de discussão. O desenrolar dessa discussão revelou-se em um excelente momento para oportunizar o protagonismo estudantil, uma vez que os conhecimentos iniciais dos estudantes sobre o assunto da Bioquímica da Célula foram mobilizados para a construção de outros saberes. Tais constatações se expressam nas compreensões e posicionamentos de maneira crítica e reflexiva dos estudantes para a busca de soluções, o que os proporcionou participarem ativamente da construção das próprias aprendizagens. Essa é uma característica de um ensino investigativo, em que o estudante é envolvido no processo de ensino e aprendizagem para consolidar os conhecimentos construídos. 
Também como diagnóstico desse estudo, verificamos um aumento representativo no conhecimento dos estudantes acerca dos conteúdos abordados, mediado pelo LV PhET Comer e Exercitar-se, que permitiu simular, visualizar e observar o fenômeno em estudo ao oportunizar situações importantes para a compreensão deles sobre os assuntos discutidos, significativos para consolidar novas formas de aprendizagem. Assim, cabe destacar, ainda, dois pontos quanto ao uso das simulações do LV PhET Comer e Exercitar-se. Quanto ao primeiro, foi possível constatar o quanto essa ferramenta digital encanta os jovens estudantes causando curiosidade, entusiasmo, motivação, engajamento, interação e colaboração, características importantes para uma aprendizagem dinâmica e significativa. Quanto ao segundo, diz-se a respeito do fato de eles reconhecerem essa tecnologia como uma forma de descontrair e brincar enquanto aprendem. Essa situação foi observada durante a realização dos estudos de caso propostos. Vale ressaltar, que mesmo depois de terem concluído os estudos de caso eles passaram a executar outras simulações, rindo e se divertindo com os resultados obtidos dessas simulações, o que permite dizer que o LV PhET Comer e Exercitar-se possibilitou trazer ludicidade à prática educativa, ou seja, aprender brincando, sem que os custos possam inviabilizar sua aplicação na realidade da Educação Básica de nossas escolas públicas.

Além do laboratório usado nesse estudo, o projeto Physics Educacional Technology (PhET), desenvolvido pela Universidade do Colorado, disponibiliza atualmente em sua plataforma sem custo dezenove laboratórios na área de Biologia. Podem ser visualizados no próprio browser como Firefox, Internet Explore ou Google Chrome ou baixados no computador, sendo necessário para sua utilização a instalação dos programas Java e o Adobe Flash Player no computador. Alguns desses laboratórios estão disponíveis na linguagem de programação HTML5, como, por exemplo, os laboratórios Fundamentos da Expressão Genética, Neurônio e Seleção Natural, o que torna possível executar essas simulações em smartphones facilitando assim o uso dessa ferramenta pedagógica em sala de aula, haja vista que muitos estudantes possuem smartphones.

Por fim, essas breves reflexões permitem afirmar que o uso do laboratório virtual é uma ferramenta estratégica e eficaz para uma abordagem investigativa. Quando usado didaticamente e adequadamente pode construir meios para aprendizagens dinâmicas por despertar a curiosidade e o interesse em aprender. Assim, consideramos que esse estudo contribuiu para ratificar as benesses dessa ferramenta tecnológica e educacional para o ensino de Biologia, bem como nos deixa no desafio de criar outras situações de aprendizagem que continuem explorando as diversas estratégias de ensino com o uso das tecnologias aplicadas à educação.

\section{Agradecimentos}

Aos estudantes participantes, aos seus responsáveis e à escola por concordarem e viabilizarem a realização desta pesquisa; à Coordenação de Aperfeiçoamento de Pessoal de Nível Superior (CAPES) pelo apoio financeiro e ao Mestrado Profissional em Ensino de Biologia (PROFBIO) pelo processo formativo do primeiro autor.

\section{Referências}

AMARAL, É. M. H; et al., Laboratório Virtual de Aprendizagem: Uma proposta Taxonômica. Revista Novas Tecnologias na Educação - CINTED-UFRGS, v. 9, n. 2, 
2011. Disponível em: https://seer.ufrgs.br/renote/article/viewFile/24821/14771. Acesso em: 30 mar. 2020.

AUSUBEL, D. P.; NOVAK, J. D.; HANESIAN, H. Psicologia educacional. Rio de Janeiro: Interamericana, 1980.623p.

AZEVEDO, M. C. P. S. de. Ensino por Investigação: Problematizando as Atividades em Sala de Aula. In: CARVALHO, A. M. P. de. (org.). Ensino de Ciências: unindo a pesquisa e prática. São Paulo: Cengage Learning, 2015. p. 19-34.

BELLONI, M. L. O que é mídia-educação. Campinas: Autores Associados, 2005.

BONILLA, M. H.; PRETTO, N. de L. Política educativa e cultura digital: entre práticas escolares e práticas sociais. Perspectiva, Florianópolis, v. 33, n. 2, p. 499-521, dez. 2015.

BRAGA, M. Realidade virtual e educação. Revista de biologia e ciências da terra, v. 1, n. 1, 2001.

BRASIL. Base Nacional Comum Curricular. Brasília: Ministério da Educação, 2018. Disponível em:

http://basenacionalcomum.mec.gov.br/images/BNCC_EI_EF_110518_versaofinal_site.pdf. Acesso em: 02 mar. 2020.

BRITO, L. O. de.; FIREMAN, E. C. Ensino de ciências por investigação: uma proposta didática "para além" de conteúdos conceituais. Experiências em Ensino de Ciências. v. 13, n. 5, p. 462-479, 2018.

COSTA, A. C. G. da.; VIEIRA M. A. Protagonismo juvenil: adolescência, educação e participação democrática. 2. ed. São Paulo: FTD, 2006.

COSTA, I. Novas tecnologias e aprendizagem. 2. ed. Rio de Janeiro: Wak, 2014.

FERRAZ, A. T.; SASSERON, L. H. Propósitos epistêmicos para a promoção da argumentação em aulas investigativas. Investigações em Ensino de Ciências, v. 22, n. 1, p. 42-60, 2017.

FONSECA, M. et al., Virtual laboratory: an experimental-based educational activity on mechanics. Revista Brasileira de Ensino de Física, v. 35, n. 4, p. 1-10, 2013.

FREITAS, J. C. R. de. Ensino de Ciências por Investigação: problematizando a temática Sexualidade através da Sequência Didática Interativa. In: ENCONTRO NACIONAL DE PESQUISA EM EDUCAÇÃ̃ EM CIÊNCIAS, 10., 2015, Águas de Lindoia. Anais [...]. Águas de Lindoia: ABRAPEC, 2015.

GOMES, K. V. G.; RANGEL, M. Relevância da disciplina bioquímica em diferentes cursos de graduação da UESB, na cidade Jequié. Revista Saúde Com, v. 2, n. 1, p. 161-168, 2006.

GOMES, L. M. J. B.; MESSEDER, J. C. Revista digital com temas bioquímicos: um material midiático para aulas de biologia. In: CONGRESSO IBERO-AMERICANO DE CIÊNCIAS, TECNOLOGIA, INOVAÇÃO E EDUCAÇÃO, 2014, Buenos Aires. Anais [...]. Buenos Aires, 2014. 
GOMES, S. D. S. Infância e tecnologia. In: COSCARELLI, C. V. (org.). Tecnologia para aprender. 1. ed. São Paulo: Parábola Editorial, 2016. p. 46-58.

GÓMEZ, Á. I. P. Educação na era digital: a escola educativa. Porto Alegre: Penso, 2015.

GREGÓRIO, E. A.; OLIVEIRA, L. G.; MATOS, S. A. Uso de simuladores como ferramenta no ensino de conceitos abstratos de Biologia: uma proposição investigativa para o ensino de síntese proteica. Experiências em Ensino de Ciências, v. 11, n. 1, p. 101-125, 2016.

HERPICH, F.; TAROUCO, L. M. R. Engajamento de usuários em mundos virtuais: Uma análise teórica-prática. RENOTE, v. 14, n. 1, 2016.

KENSKI, V. M. Educação e tecnologias: O novo ritmo da informação. 8. ed. Campinas: Papirus, 2011.

LAZALDE, A. R.; MONREAL, M. R.; BONILLA, M. E. P. Experimentación virtual con el simulador dosis-respuesta como herramienta docente en biología. Apert. (Guadalaj., Jal.), Guadalajara, v. 8, n. 2, p. 22-37, 2016. Disponível em:

http://www.scielo.org.mx/scielo.php?script=sci_/.../1665-

61802016000300022\&lng=es\&nrm=iso. Acesso em: 30 mar. 2020.

LOPES, L. A. Olhar digital na escola: a cibercultura nas aulas de Biologia em uma escola da periferia de Canoas, RS. Revista Tecnologia na Educação, n. 14, p. 1-12, 2016.

MACÊDO, J. A. de; DICKMAN, A. G.; ANDRADE, I. S. F de. Simulações computacionais como ferramentas para o ensino de conceitos básicos de eletricidade. Caderno Brasileiro de Ensino de Física, v. 29, n. Especial 1, p. 562-613, set. 2012.

MELO, R. C. de; OSSO JR., J. A. Laboratórios virtuais e ambientes colaborativos virtuais de ensino e de aprendizagem: conceitos e exemplos. Revista de Informática Aplicada, v. 4, n. $2,2008$.

MENDES, A.; SANTANA, G.; JÚNIOR, E. P. O uso do software PhEt como ferramenta para o ensino de balanceamento de reação química. Revista Areté/Revista Amazônica de Ensino de Ciências, v. 8, n. 16, p. 52-60, 2017.

MONTANINI, S. M. P.; MIRANDA, S. do C. de; CARVALHO, P. S de. O ensino de ciências por investigação: abordagem em publicações recentes. Revista Sapiência: Sociedade, Saberes e Práticas Educacionais, v. 7, n. 2, p. 288-304, jan./jul. 2018.

MORAN, J. M. Novas tecnologias e mediação pedagógica. 21. ed. São Paulo: Papirus 2013.

OLIVEIRA, L. S. C. de et al., Apresentação metodológica com uso de tecnologia digital no ensino de ciências. Revista Sustinere, v. 5, n. 1, p. 68-89, 2017.

OLIVEIRA, M. M. de. Sequência Didática Interativa no processo de formação de professores. Rio de Janeiro: Vozes, 2013.

PHET INTERACTIVE SIMULATION. [2021]. Disponível em: https://phet.colorado.edu/pt_BR/simulation/legacy/ eating-and-exercise. Acesso em: 15 jul. 2020. 
PRENSKY, M. Nativos digitais, imigrantes digitais. On the horizon, v. 9, n. 5, p. 1-6, 2001.

PRENSKY, M. O papel da tecnologia no ensino e na sala de aula. CONJECTURA: filosofia e educação, v. 15, n. 2, 2010.

SANTOS, J. C. dos.; DICKMAN, A. G. Virtual and real experiments: a proposal to teach electricity in High School. Revista Brasileira de Ensino de Física, v. 41, n. 1, 2019.

SANTOS, P. S. dos.; COSTA, L. E. D. L. A inserção do laboratório virtual como recurso didático no curso de licenciatura em Física. Somma, Teresina /PI, v. 1, n. 2, p. 83-91, jan./jun. 2016.

SASSERON, L. H.; DE CARVALHO, A. M. P. Almejando a alfabetização científica no ensino fundamental: a proposição e a procura de indicadores do processo. Investigações em ensino de ciências, v. 13, n. 3, p. 333-352, 2008.

SASSERON, L. H. Interações discursivas e investigação em sala de aula: o papel do professor. In: CARVALHO, A. M. P. de. (org.). Ensino de ciências por investigação: condições para implementação em sala de aula. São Paulo: Cengage Learning, 2013. p. 41-62.

SILVA, I. P. da.; NUNES, E. T.; MERCADO, L. P. L. Experimentos virtuais no estágio supervisionado de Física. Caderno Brasileiro de Ensino de Física, v. 33, n. 3, p. 1115-1144, 2016.

SILVA, R. L. da.; BARBOSA, A. R. Ensino de ciências e tecnologias digitais: desafios e potencialidades. Ciclo Revista, v. 1, n. 2, 2016.

TRIVELATO, S. L. F.; TONIDANDEL, S. M. R. Ensino por investigação: eixos organizadores para sequências de ensino de biologia. Ensaio Pesquisa em Educação em Ciências. Belo Horizonte, v. 17, p. 97-114, nov. 2015.

VALENTE, J. A. As tecnologias e a verdadeira inovação na educação. In: ALMEIDA. M. E. B. de.; DIAS, Paulo; SILVA, B. D. da. (org.). Cenários de inovação para educação na sociedade digital. São Paulo: Edições Loyola, 2013. p. 35-46.

WORLD HEALTH ORGANIZATION. Obesity: preventing and managing the global epidemic. Geneva: World Health Organization, 2000.

ZABALA, A. A prática educativa. Porto Alegre: ArtMed, 1998.

ZARA, R. A. Reflexão sobre a eficácia do uso de um ambiente virtual no ensino de Física. In: ENCONTRO NACIONAL DE INFORMÁTICA E EDUCAÇÃO, 2., 2011, Cascavel. Anais [...]. Cascavel, 2011.

Recebido em julho de 2021.

Aprovado em outubro de 2021. 


\section{APÊNDICE A: Questionário pré-teste - Conhecimentos básicas de nutrição e alimentação}

1) Qual o critério que você utiliza para escolher os alimentos em cada refeição?
a) Cheiro
b) Calorias
c) Fácil acesso
d) Sabor
e) Saúde
f) Outros

2) Você sabe o que é um macronutriente? ( ) Sim

( ) Não

3) Os alimentos abaixo são ricos principalmente em qual macronutriente? Escreva o nome do macronutriente na coluna correspondente ou marque com um X em uma das outras alternativas.

\begin{tabular}{|c|c|c|c|}
\hline Alimentos & Macronutriente & Não tenho certeza & Não sei \\
\hline \multicolumn{4}{|l|}{ Arroz } \\
\hline \multicolumn{4}{|l|}{ Bacon } \\
\hline \multicolumn{4}{|l|}{ Banana } \\
\hline \multicolumn{4}{|l|}{ Batata } \\
\hline \multicolumn{4}{|l|}{ Carne de frango } \\
\hline \multicolumn{4}{|l|}{ Carne de hambúrguer } \\
\hline \multicolumn{4}{|l|}{ Leite } \\
\hline \multicolumn{4}{|l|}{ Manteiga } \\
\hline Queijo & & & \\
\hline
\end{tabular}

4) Os carboidratos são moléculas orgânicas formadas principalmente por carbono, hidrogênio e oxigênio. Considerando os conhecimentos sobre bioquímica da célula e nutrição qual a principal função dos carboidratos?
a) Energéticos
b) Estimulantes
c) Estruturais
d) Hidratação
e) Reguladores

5) Os lipídeos são moléculas orgânicas formadas pela associação entre um ácido graxo e um álcool, são insolúveis em água e solúveis em certas substâncias orgânicas, tais como álcool, éter e acetona. Considerando os conhecimentos sobre bioquímica da célula e nutrição qual a principal função dos lipídeos?
a) Energéticos
b) Estimulantes
c) Estruturais
d) Hidratação
e) Reguladores

6) As proteínas são moléculas orgânicas formadas pela polimerização de aminoácidos. Considerando os conhecimentos sobre bioquímica da célula e nutrição qual a principal função das proteínas?
a) Energéticos
b) Estimulantes
c) Estruturais
d) Hidratação
e) Reguladores

7) A pirâmide alimentar é utilizada para mostrar visualmente a proporção adequada dos macronutrientes de uma dieta balanceada. Marque a alternativa que contém, em ordem decrescente (da maior quantidade para a menor), a necessidade de macronutrientes a ser consumida em um dia por um adolescente.
a) Carboidratos
b) Carboidratos
c) Lipídeos
d) Proteínas
Proteínas
Proteínas
Lipídeos
e) Proteínas
Lipídeos
Lipídeos
Carboidratos
Carboidratos
Carboidratos
Lipídeos

8) Apenas a prática de atividade física interfere no metabolismo ao ponto de tirar a pessoa da condição de sobrepeso ou obesidade.
( ) Discordo muito
( ) Discordo
( ) Nem concordo, nem discordo
( ) Concordo
( ) Concordo muito

9) Você pratica alguma atividade física regularmente durante a semana? ？ ( ) Sim （ ) Não

10) Caso tenha respondido sim, quantas vezes durante a semana você pratica alguma atividade física?
( ) Uma
( ) Duas
( ) Três
( ) Mais que três

11) Quais os alimentos que você costuma comer no café da manhã?

12) Quais os alimentos que você costuma comer no almoço?

13) Quais os alimentos que você costuma comer no jantar? 


\section{APÊNDICE B: Questionário pós-teste - Conhecimentos básicas de nutrição e alimentação}

1) O que determina a escolha dos alimentos em suas refeições?
a) Fácil acesso
b) Calorias
c) Saúde
d) Cheiro
e) Sabor
f) Outros

2) Os carboidratos e os lipídeos conhecidos como macronutrientes são moléculas orgânicas formadas principalmente por carbono, hidrogênio e oxigênio. Considerando os conhecimentos sobre bioquímica da célula e nutrição essa afirmação é: ( ) Falsa ( ) Verdadeira. Comente sua resposta

3) Os alimentos abaixo são ricos em maior quantidade em qual macronutriente? Escreva o nome do macronutriente na coluna correspondente ou marque com um X em uma das outras alternativas.

\begin{tabular}{|l|l|l|l|}
\hline \multicolumn{1}{|c|}{ Alimentos } & Macronutriente & Não tenho certeza & Não sei \\
\hline Peixe & & & \\
\hline Ovo & & & \\
\hline Manteiga de garrafa & & & \\
\hline Batata doce & & & \\
\hline Óleo de soja & & & \\
\hline Macarrão & & & \\
\hline Carne de boi & & & \\
\hline Banana comprida & & & \\
\hline Bacon & & & \\
\hline
\end{tabular}

4) Carlos é um adolescente que tem 17 anos e há três meses passou a frequentar a academia. Para que ele tenha energia para realizar sua atividade física adequadamente qual o nome do macronutriente que ele deve consumir?

5) Mário é um adolescente de 16 anos que apresenta sobrepeso. Sua mãe levou-o ao nutricionista e foi verificado que sua dieta estava muito desequilibrada. Ele consumia muitos alimentos como manteiga e bacon, além de comidas fritas, ricas em gorduras e óleos. Qual é o nome do macronutriente presente em sua alimentação que deve ser reduzido da sua dieta para que seu peso seja normalizado e possa viver mais saudável?

6) Pedro é um adolescente de 15 anos que tem apresentado um cansaço incomum e sua mãe decidiu levá-lo ao médico. Ele solicitou alguns exames e o encaminhou ao nutricionista. Diante dos exames e da avaliação nutricional percebeu-se que Pedro apresenta uma deficiência de alguns aminoácidos essenciais devido à falta de ingestão de alimentos como carne de boi, peixes, soja e ovo. Qual o nome do macronutriente presente nesses alimentos que deve ser adicionado à sua dieta?

7) A pirâmide alimentar representada abaixo é utilizada para mostrar visualmente a proporção adequada dos macronutrientes de uma dieta balanceada. Marque a alternativa que contém, em ordem decrescente (da menor quantidade para a maior quantidade), a necessidade de macronutrientes a ser consumida em um dia por um adolescente.
a) Carboidratos b) Carboidratos
c) Lipídeos
d) Proteínas
e) Proteínas
Lipídeos
Proteínas
Proteínas
Lipídeos
Carboidratos
Proteínas
Lipídeos
Carboidratos
Carboidratos
Lipídeos

Comente sua resposta

8) Em uma situação de sobrepeso ou de obesidade, apenas a prática de atividade física pode influenciar no metabolismo ao ponto de tirar a pessoa dessa condição.

( ) Discordo muito

( ) Discordo

( ) Nem concordo, nem discordo

( ) Concordo

( ) Concordo muito

Comente sua resposta

9) Você pratica alguma atividade física regularmente durante a semana? ( ) Sim ( ) Não 
Revista de Educação, Ciência e Tecnologia

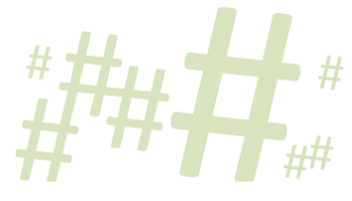

10) Caso tenha respondido sim, quantas vezes durante a semana você pratica alguma atividade física?
( ) Uma
( ) Duas
( ) Três
( ) Mais que três

11) Quais os alimentos você costuma comer no café da manhã?

12) Quais os alimentos você costuma comer no almoço?

13) Quais os alimentos você costuma comer no jantar? 